\title{
BEST AVAILABLE TECHNIQUES AS ENVIRONMENTAL SAFETY ENHANCEMENT INSTRUMENTS
}

\author{
Michael Begak ${ }^{1}$, Tatiana Guseva ${ }^{2}$, Yana Molchanova ${ }^{3}$, Alexander Malkov ${ }^{4}$
}

\begin{abstract}
Environmental safety enhancement is an important objective for any state. It is vital for the Russian Federation, where economic activities resulted in environmental deterioration. Current development has to provide both for the growth of the national economy and for the minimization of negative environmental impacts. These issues could be addressed via development and implementation of the National Environmental Strategies, which have to become a basis for setting national targets and implementing modern instruments of environmental safety. European experience proves that the Best Available Techniques (BAT) are considered as instruments applicable to improve environmental performance and resource efficiency for major enterprises. Main components of the national environmental strategy are discussed, and prerequisites for its implementation (such as ratification of Espoo and Aarhus conventions and practical application of BAT principles in environmental regulation) are suggested as a result of the analysis of new legislative and managerial approaches emerging in Russia.
\end{abstract}

UDC Classification: 502.35, DOI: http://dx.doi.org/10.12955/cbup.v3.613

Keywords: environmental safety, risk, hazard, Best Available Techniques, National Environmental Strategies

\section{Introduction}

Environmental safety can be defined as a state of security of the environment and human being, as well as human interests, from possible dangers, both anthropogenic and natural. In any country, environmental safety is an integral part of the national safety and needs to be managed at all levelsfrom an organizational level to the global ecosystem level. Economic development makes it crucially important to develop internationally approved instruments, which can be introduced by the state and applied at the organizational level.

\section{Environmental Safety Concept}

Back in the 1980s, a well-known Russian environmental lawyer, Oleg Kolbasov (Kolbasov, 1988), defined environmental safety as "a system of measures aimed at eliminating the threat of mass losses of human lives as a result of an adverse anthropogenic change of the state of environment and formation of conditions under which humans (as a biological species) cannot satisfy their physiological and social needs." Later on, the Interagency Commission on Environmental Safety (Proceedings, 1994) defined environmental safety as "a state of protection of natural environment and vital interests of citizens, society, the state from internal and external impacts, adverse processes and trends in development that threaten human health, biodiversity and sustainable functioning of ecosystems, and survival of humankind." In the UK, environmental security is interpreted as "an environment protected from harm or adverse effects from natural or human processes so that resources are sustained for future generations" (Gormley, Pollard, \& Rocks, 2011). As referred to very often in various research papers and reports, environmental safety is often understood and interpreted differently by various authors. Some researchers believe that environmental safety should mean a complete, absolute exclusion of any danger (Rusakov, 2006). This position is hardly agreeable, since environmental safety often reminds us of two factors: risk (the potential consequence(s) of a hazard

\footnotetext{
${ }^{1}$ Mikhail Begak, St. Petersburg Scientific Research Centre for Environmental Safety of Russian Academy of Sciences, mbegak@gmail.com

2 Tatiana Guseva, Department for Management and Marketing, D. Mendeleyev University of Chemical Technology of Russia, tguseva@muctr.ru

3 Yana Molchanova, Department for Management and Marketing, D. Mendeleyev University of Chemical Technology of Russia, yanamolchanova@gmail.com

4 Alexander Malkov, Department for Management and Marketing, D. Mendeleyev University of Chemical Technology of Russia, malkov@ muctr.ru
} 
combined with their likelihoods/probabilities) and hazard (a situation or biological, chemical or physical agent that may lead to harm or cause adverse effects). Then, an environmental risk is the probability value of an undesirable event and its consequences that arise from a spontaneous natural origin or from a human action that is transmitted through the environment. For people, researchers, first of all, consider diseases to be caused by environmental risks. According to the World Health Organization, environmental factors are a root cause of a significant disease burden; an estimated 25\% of death and disease globally is linked to environmental hazards (Priority environment and health risks, 2005).

\section{Environmental Services and Natural Capital}

Changes in the state of the environment (such as very serious cases of water pollution, land contamination, and biodiversity losses) causing effects on ecosystems themselves and on human beings are classified as environmental damage. Economists tend to make a link between environmental damage and worsening of ecosystem services, while ecosystem services are understood as the benefits people obtain from ecosystems and include provisioning services, such as food and water; regulating services, such as flood and disease control; cultural services, such as ritual, recreational, and cultural benefits; and supporting services, such as nutrient cycling, that maintain the conditions for life on Earth (Ecosystems and Human Well-being, 2003). There is another term, which needs to be defined. Natural capital is the stock of ecosystems that yields a renewable flow of goods and services that underpin the economy and provide inputs and direct and indirect benefits to businesses and society. Natural capital is a subset of environmental, social, and governing factors that can be regarded as material for financial institutions, mainly through their allocations of capital to companies through loans and investments, or premiums as part of insurance contracts (Natural Capital Declaration, 2013; Titova, 2014).

\section{Acceptable Risk Concept}

Back in the 1970s, a concept of acceptable risk emerged in various countries. In Russia, the concept was studied by academician Valery Legasov and his research team. Usually, acceptable risk refers to the level of potential losses that a society or community considers acceptable given the existing social, economic, political, cultural, technical, and environmental conditions (Disaster Risk Assessment, 2010). At an earlier stage, it was believed that environmental risk, unlike the case of radiation, studied by the Russian academician Legasov (1984) can be equal to zero. The very idea was based on the assumption that there is a threshold limit value of a chemical substance below which people can be exposed to without adverse health effects. And, vice versa, there is no threshold limit value of ionizing radiation, which makes it impossible to ensure zero risk from it. In ecology, zero risk is often associated with Le Chatelier-Braun principle (Strutt, 2009). This principle states: "if any change is imposed on a system that is in equilibrium, then the system tends to adjust to a new equilibrium counteracting the change. In case of an ecosystem, this should mean that negative changes in its state occur only when an external change value is higher than its threshold."

Since the 1990s, the concept of threshold values relating to chemical substances has been significantly changed. Thus, Air quality guidelines for Europe stated: "it should be noted that the risk estimates for carcinogens do not indicate a safe level, but they are presented so that the carcinogenic potencies of different carcinogens can be compared and an assessment of overall risk made" (WHO, 2000). Thus, for example, the lifetime risk of leukemia caused by breathing air containing benzene in the concentration of 1 microgram per 1 cubic metre is equal to $6^{*} 10^{-6}$. Therefore, when selecting a job at a chemical plant or even at a fuel filling station, where benzene concentrations may be many times higher, one should assess the acceptability of personal risk in getting leukemia. 
Since the last decade, Le Chatelier-Braun principle has been seriously questioned (Leskov, 2006). Modern scientific understanding assumes that ecosystems should be considered as opened, selforganized systems, evolving in accordance with synergy principles. Sustainability of such systems is based upon non-linear feedback mechanism; a bifurcation occurs when a change made to the parameter values of a system causes a sudden "qualitative" change in its state or behavior. A wellknown decision-making example falling into the category of preventing a bifurcation is the international agreement on climate change mitigation. According to this agreement, it is necessary to find and agree upon an acceptable level of greenhouse gas emissions that would allow biosphere to sustain for a long time without a significant growth of the global temperature and, thereby, without a bifurcation.

Acceptable risk is a conventional term; its value is defined by the society. For example, in the Netherlands, risk levels exceeding $10^{-6}$ are considered to be unacceptable, while risk levels below $10^{-8}$ are considered negligible. Since the 1970s, this level of $10^{-6}$ has been regarded as something of a gold standard. But, maintaining such a risk level is often too expensive for the society. This is why the US Environmental Protection Agency (EPA) typically uses a target reference risk range of $10^{-4}$ to $10^{-6}$ for carcinogens in drinking water, which is in line with World Health Organization guidelines for drinking water quality. In this regard, wherever practical, base guideline values are $10^{-5}$ for genotoxic carcinogens on the upper bound estimate of an excess lifetime cancer risk (Byrd \& Cothern, 2000). In Russia, acceptable risk levels are recommended by the Guidance on the Assessment of Risks of Chemical Substances on Public Health (Guidance, 2004). This Guidance defines acceptable risk as "the level of emerging of an unfavourable effect, which does not require any additional measures to decrease it; acceptable risk is insignificant compared to risk levels existing in the common everyday human activities and life". Acceptable risk levels caused by chemical contaminants polluting the environment are recommended to be kept between $10^{-6}$ and $10^{-4}$. Individual lifetime risk for professional groups (occupational risk) can be between $10^{-4}$ and $10^{-3}$. Such professional risk levels require for special health-promoting (improving) measures for employees and are not acceptable for general public. Risk levels equal and exceeding $10^{-3}$ are not acceptable neither for general public nor by employees, and require urgent measures. Target risk levels for settlements set in Russia are in the range of $10^{-6}-10^{-5}$.

Similar to the acceptable risk term, it is possible to come up with the definition of acceptable damage; it is a damage level, which society considers possible to tolerate and compensate, either naturally or monetarily (based on an agreement with an entity causing this damage). This definition speaks for itself and explains that acceptable damage like acceptable risk is a conventional term. Since negative impacts can be associated with acceptable risk levels, it is suggested that acceptable damage corresponds to the acceptable risk level.

\section{Instruments for Environmental Risk Minimization}

Preventing unacceptable risks and unacceptable damage is the responsibility of the State and should be guaranteed by its institutes. Thus, Russian Constitution states: "Everyone shall have the right to favorable environment, reliable information about its state and for a restitution of damage inflicted on his health and property by ecological transgressions." Besides, it is guaranteed as "State - the Russian Federation" stated: "everyone shall have the right for a state compensation for damages caused by unlawful actions (inaction) of bodies of state authority and their officials" (Constitution, 1993). Following this logic, environmental safety should become a special institute of the society, which guarantees preventing intolerable risks and damages, both to the environment and public health associated with environmental factors. 
The society seeks to make the necessary provisions for its members and for the environment itself. In other words, the society tries to preserve or to improve quality of ecosystem services and to build up the natural capital. Social structures setting environmental safety targets include the State itself, various forms of local self-government, and, in the federal state, federation subjects. Thus, concerning environmental safety, these social structures should aim to guarantee prevention of risk and damage to the environment and public health (caused by environmental factors). Here, we should speak of intolerable risk and damage; but since the state shall not set objectives associated with any damage (even minimal one), we omitted the term intolerable in the proposed definition above.

Environmental risk and environmental damage are often interrelated. Concerning industrial safety, technological and technical solutions are aimed at the preventing major accidents and at limiting the consequences of such accidents on human health and the environment. As a result, major accidents occur less often than minor ones, and higher risk corresponds to the lower damage. In terms of environmental safety, we should speak of preventing damage rather than relieving its consequences. Preventive measures generally cost less when compared with monetary losses incurred from the environmental damage. What instruments can be used by the State to guarantee the environmental safety of the society? First of all, well-established preventive instruments as Strategic Environmental Assessment (SEA), Environmental Impact Assessment (EIA), and so called environmental expertise (SEA and/or EIA quality assessment) need to be applied. As far as SEA is concerned, Russia has to ratify Espoo Convention on Environmental Impact Assessment in a transboundary context, which sets out the obligations to assess the environmental impact of certain activities at an early stage of planning as well as Kyiv Protocol, which requires its Parties to evaluate the environmental consequences of their official draft plans and programs. Regarding environmental expertise, this robust instrument was brought back to the Russian legislation when respective changes were introduced into the Federal Law "On Environmental Protection" (Federal Law No. 7, 2002). Other valuable environmental safety instruments include Environmental Management Systems (EMS) and Energy Management Systems (EnMS), which conform to the requirements of respective ISO standards: ISO 14001:2004 and ISO 50001:2011. Organizations seeking certification of their EMS and EnMS guarantee that they apply in practice these tools for managing their environmental and energy aspects, thereby minimizing their impacts on the environment. Since EMS and EnMS help to improve environmental performance and energy efficiency of an organization, their implementation can be considered as an indicator of a better environmental (and "natural") behavior of a company.

\section{Best Available Techniques and Integrated Environmental Permits}

In Russia, a new environmental safety instrument for larger installations, namely Integrated Environmental Permits (IEP), based on Best Available Techniques (BAT), were introduced at the beginning of 2015. Key parameters characterizing BAT include specific consumption (energy, raw materials, water, etc.) and emission levels of pollutants into air, water, and soil, obtained under normal operating conditions, expressed as an average over a given period of time, under specified reference conditions. Similar to the EU experience, Russia is planning to develop a wide number (47) of Reference Books (BREFs) on Best Available Techniques. The first 10 BREFs are already being prepared and shall be completed by the end of 2015. In Russia, these documents form an integral part of the national standardization system, and are being formed by Sectoral Technical Groups the National BAT Bureau functioning under the Federal Agency for Technical Regulation and Metrology (Rosstandard). Collected data on resource efficiency and environmental performance of industrial and agricultural sectors will form the necessary basis for the national benchmarking and for the identification of national companies leading in the field of environmental safety provision (Guseva, 
Begak, Molchanova, \& Averochkin, 2014). The following characteristics of BATs on environmental safety shall be considered while running a comparative study of Russian installations:

- practical use of cleaner (low waste) technologies;

- the nature and quantities of foreseeable emissions from the installation into each medium, as well as identification of significant effects of the emissions on the environment;

- the raw and auxiliary materials, other substances, and the energy used by the installation;

- application of substances, which are least hazardous to the environment and public health;

- measures for the prevention, preparation for re-use, recycling, and recovery of waste;

- risks of industrial accidents and measures taken to prevent them and limit their consequences;

- implementation of EMS and possession of respective certificates.

Both the development of BREFs and future identification of procedures, associated with granting Integrated Permits, will involve a wide range of organizations and independent experts. Therefore, it is very important to gain common understanding of key features of BATs as environmental safety enhancement instruments. Main provisions of this approach include:

- Best Techniques mean most effective in achieving a high general level of protection of the environment as a whole and rational use of natural resources;

- Available Techniques mean those developed on a scale, which allows implementation in the relevant industrial sector, under economically and technically viable conditions; Available Techniques are those practically implemented at least at two installations;

- Techniques include both the technology, technical, and managerial means used and the way in which the installation is designed, built, maintained, operated, and decommissioned;

- BAT means environmental modernization of larger industrial and agricultural installations causing significant negative impacts on the environment and public health;

- BAT means innovative solutions, but exclusively those that serve the overall objective of minimizing negative environmental impacts and providing for better environmental safety;

- $B A T$ is an environmental safety warranty of an enterprise (issued in a form of an Integrated Environmental Permit or a certificate);

- In the medium term and longer term perspectives, BAT means growth of natural capital and enhancement of ecosystem cervices.

- BAT does not account for import substitution, since technological, technical and managerial measures providing for reduction of environmental impacts are international.

BAT implementation (transition) is a longer-term process; it is expected that first IEPs will be issued in Russia not earlier than 2019. In the meantime, voluntary certification of enterprises against BAT requirements could help to promote the concept and improve environmental performance of leading industries. To obtain the voluntary BAT certification, Rosstandard should develop the respective procedures. According to the Russian legislation, voluntary certification systems can be registered, and registrars can be authorized to issue BAT certificates. The first attempt to form such a system was undertaken by the National Association of Builders, which established a certification system offering opportunities to register not only EMS and EnMS, but also compliance with BAT requirements set by voluntary national standards for the production of ceramic building materials and cement. 


\section{National Environmental Safety Strategy}

It is necessary to emphasize that implementation of the National Environmental Safety Strategy requires to gain wider public participation and public access to data of the National Environmental Monitoring Information Register. This Register shall be developed in accordance with the Federal Law "On Environmental Protection" (Federal Law No. 7, 2002). Besides that, public participation instruments should strengthen the ratification of the Aarhus Convention on Access to Information, Public Participation in Decision-Making, and Access to Justice in Environmental Matters. Therefore, indicators of the Environmental Safety Strategy implementation should include such parameters as: number of conducted SEA, EIA, and environmental expertise procedures; number of organizations certified against EMS and EnMS standards (such as ISO 14001:2004 and ISO 5001:2011); number of organizations complying with BAT requirements (including those registered voluntarily); number of installations with granted IEPs.

\section{Conclusion}

In summary, we suggest a list of the following measures aimed at the implementation of the National Environmental Safety Strategy:

- ratification of Espoo Convention and Protocol on Strategic Environmental Assessment;

- ratification of Aarhus Convention and urgent formation of the National Environmental Monitoring Information Register - an open access to this Register data should be provided for all stakeholders;

- promotion of voluntary certification of Environmental and Energy Management Systems and development of the Green Public Procurement Scheme requiring EMS and EnMS registration as an obligatory tender condition;

- development of rules and procedures of voluntary BAT certification for organizations of key economic sectors, and providing for BAT certificate or EIP requirement in the Green Public Procurement Scheme.

\section{References}

Byrd, D. M., \& Cothern, C. R. (2000). Introduction to Risk Analysis: A Systematic Approach to Science-Based Decision Making. Houston: ABS Group.

Disaster Risk Assessment (2010). UNDP. Retrieved February 25, 2015, from http://www.undp.org/content/dam/undp/library/ Disaster/Risk?Assessment.pdf

Ecosystems and Human Well-being: a Framework for Assessment. (2003). A Report of the Conceptual Framework Working Group of the Millennium Ecosystem Assessment. Retrieved February 25, 2015, from http://pdf.wri.org/ecosystems_human_ wellbeing.pdf

Gormley, Á., Pollard, S., \& Rocks, S. (2011). Guidelines for Environmental Risk Assessment and Management. Green Leaves III. The Department for Environment, Food and Rural Affairs. Retrieved March 5, 2015, from https://www.gov.uk/government/uploads/system/uploads/attachment_data/file/69450/pb13670-green-leaves-iii-1111071.pdf).

Guidance on the Assessment of Risks of Chemical Substances on Public Health [Guidance] (2004). Rukovodstvo po otsenke riska dlia zdorovya naseleniya pri vozdejstvii khimicheskikh veschestv [Guidance on the Assessment of Risks of Chemical Substances on Public Health]. Retrieved March 6, 2015, from http://www.complexdoc.ru/ntdtext/544120/5.

Guseva, T., Begak, M., Molchanova, Y., \& Averochkin, E. (2014). Integrated Pollution Prevention and Control: Current Practices and Prospects for the Development in Russia. 14th SGEM GeoConference on Ecology, Economics, Education and Legislation, 2, 391-398. doi: 10.5593/SGEM2014/B52/S20.052.

Kolbasov O. V. (1988). kontsepstija ekologicheskok bezopasnosti. Sovetskoje Gosudarstvo I pravo. No 12. S. 45-55. [Environmental Safety Concept. Soviet State and Justice, 12, 45-55]. 
Legasov, V. A., Demin, V. F., \& Shevelev, Ya. V. (1984). Ekonomika bezopasnosti jadernoj energetiki [Economic Aspects of Nuclear Energy Safety]. Institute for Nuclear Power, 4072(3), 48.

Leskov, L. V. (2006). simergizm; philosophskaja paradigm XXI veka [Synergism: A Philosophic Paradigm of the 21st Century]. Moscow: Economic Publishing House.

Priority environment and health risks. (2005). Retrieved February 25, 2015, from http://www.who.int/heli/risks/en/

Proceedings of the Interagency Commission on Environmental Safety [Proceedings] (1994). Environmental Security of Russia, 2, 55-58.

Rusakov, M. A. (2006). Ecologicheskaya bezopasnost'sovremennoj Rossii: dissertatsiya [Environmental Safety in Modern Russia]. Retrieved March 02, 2015, from http://www.dslib.net/teoria-prava/jekologicheskaja-bezopasnost-sovremennojrossii.html.

Russian Federation Federal Law [Federal Law No. 7] (2002). Russian Federation Federal Law No. 7-FZ “On environmental protection." Retrieved February 27, 2015, from http://faolex.fao.org/cgi-in/faolex.exe?rec_id=042689\&database=FAOLEX\& search_type=link\&table=result\&lang=eng\&format_name=@ERALL.

Strutt, J. W. (2009). The Le Chatelier-Braun Principle. Scientific Papers, 6. 1911-1919. Cambridge University Press. 475477.

The Constitution of the Russian Federation [Constitution] (1993). Retrieved March 4, 2015, from http://www.constitution.ru/en/10003000-01.htm.

The Natural Capital Declaration and Roadmap (2013). Retrieved February, 25, 2015 from: http://www.naturalcapital declaration.org/wp-content/uploads/2013/10/NCD-booklet-English.pdf.

Titova, G. V. (2014). Poniatije 'prirodnyj capital', razvitije metodologii I metodov ego economicheskopj otsenki [Natural Capital Term, Development of Methodology and Methods for its Economic Assessment]. Bulletin of Saint-Petersburg University. Series 7, 113-123.

World Health Organization [WHO] (2000). Air quality guidelines for Europe (2nd ed). European series. WHO regional publications. Retrieved February 24, 2015, from http://www.euro.who.int/_data/assets/pdf_file/0005/74732/E71922.pdf 